\title{
Analysis of Implementation Countermeasures on Customer Relation Management of Small and Medium Enterprises
}

\author{
Guoyin Chen, Songzhi Fan \\ School of business, Qingdao Binhai University, Qingdao, Shandong, 266555, China
}

Keywords: Small and medium enterprises, Customer relation management, Implementation, Strategy.

\begin{abstract}
As network information era comes, e-commerce level gain fast improvement. Under such environmental background, most small and medium enterprises have started to implement customer relation management. Although certain achievements have been gained, there are many problems in actual implementation process. Small and medium enterprises need to solve these problems. This paper deeply analyzes the key points, problems and coping strategies of implementation of customer relation management by small and medium enterprises, in the hope of better driving development of small and medium enterprises.
\end{abstract}

\section{Introduction}

Customer relation management (CRM) is the most advanced modern marketing idea in current stage. Its main idea is to regard corporate customers as important resources in corporate operation process and meet customer demand through effective analysis of customers so as to offer perfect and favorable services for customers and achieve the purpose of customers' lifetime value. Hence, CRM is widely applied in small and medium enterprises due to its advantages. It can not just apply multiple information technologies to guarantee enterprise service level, but also can provide automatic handling and solutions for enterprise business. Deep investigation of CRM becomes the problem that small and medium enterprises must consider and solve.

\section{Key problems in corporate operation process}

In the process of China's economic development and construction, the important position of small and medium enterprises should not be ignored. Massive survey data show the total number of small and medium enterprises in China account for over 90\% of all enterprises in China. Although these enterprises have a small scale, they can operate flexibly and seize good opportunities in the operation process. However, many problems still exist for small and medium enterprises to some extent. For example, their management idea falls behind; management level is short; the development ability in new project field is poor; their capital is weak ${ }^{[1]}$. Besides, market competition level boosts. Thus, to occupy a position in such background, small and medium enterprises must cognize and know the importance of customers and services according to their own features and actual conditions, and then effectively implement CRM.

\section{Ability to make a response to actual market demand}

As the competitions in industry market become increasingly fierce, relative products and services gradually tend to homogenization, so enterprises start to pay attention to actual needs of corporate customers. Enterprises can better develop in industrial competitions only when enterprises regard market as strategic orientation, and provide good services and products for the market in operation process. However, for small and medium enterprises, their construction scale and technical level are relatively insufficient. In order to improve risk resistance ability of small and medium enterprises, and increase their income, they must regard corporate customers as the core and adjust the production in accordance with market and customer needs. Meanwhile, it is required to enhance the connection between enterprise and customers, deeply know the changes in customer demand and then reach the purpose of retaining customers and mining new customers. The implementation of CRM in small and 
medium enterprises may let enterprises know customers' trend in time and make responses to market fast. In this way, the development of small and medium enterprises can be better promoted ${ }^{[2]}$.

\section{Ability to satisfy customer demand in a timely and effective manner}

Small and medium enterprises must gain and retain superior customers in the construction and development process. The purpose of CRM is to know customers' conditions, enterprise marketing situations and enterprise management state in a fast, timely and accurate way through effective analysis of customers' actual needs, product marketing, trade information and service information etc. This can help small and medium enterprises to control and manage customer relations.

\section{Ability to provide favorable services to support customer loyalty}

During construction of small and medium enterprises, customer retention and enterprises' profitability must be supported by superior services. In current stage, enterprise product homogeneity is enhancing so that enterprise competitions are not just product competitions. Original product competitions gradually change to service competitions. Thus, customer service and support are very important for most small and medium enterprises. In customer management process, customer service and support are achieved by calling system and internet etc. so the speed, accuracy and work efficiency can satisfy customers ${ }^{[3]}$. Great development of small and medium enterprises is decided by repeated purchase of original customers, new product research and development and new customer expansion. Hence, enterprises and customers should carry out good communication and management so as to improve customer loyalty and increase their repeated purchasing power.

\section{Ability to guarantee favorable and long-term development of small and medium enterprises}

Seeing from actual conditions of small and medium enterprises, they have certain flexibility, but their actual anti-risk ability is general and their lifetime is relatively short. Thus, in such new network economic background, small and medium enterprises must adjust previous operation mode according to market development rules and change product core to customer center in order to get development. Implementation of CRM in small and medium enterprises can not just improve enterprise revenue and market influence level as well as employees' sense of honor, and let employees have the sense of belonging, but also can fully motivate employees' working enthusiasm, make them put themselves into daily work and create more values for customers so as to make sure the enterprises can develop in a healthy, smooth and favorable manner ${ }^{[4]}$.

\section{Problems in application of CRM by small and medium enterprises}

According to actual conditions, it is not long to implement and apply domestic CRM. Many small and medium enterprises are still in the initial stage, so they have certain cognitive deficiency for mode and cutting-edge CRM . besides, in the practice process, many problems need to be solved. Next, these problems are analyzed in detail:

\section{Failure to effectively cognize CRM}

CRM started to rise and improve overseas. After it was cognized, it was gradually applied in marketing and gradually formed customer-cored idea. As it continuously develops and deepens, CRM is gradually combined with IT technology. It is necessary to note that Chinese small and medium enterprises introduce its advanced products rather than the idea of CRM. Thus, small and medium enterprises still have no the idea of CRM. It is very hard to achieve the goal by only depending on IT technology in the implementation process ${ }^{[5]}$. Meanwhile, this indicates since small and medium enterprises fail to effectively cognize CRM, they have certain problems in developing new customers and maintaining regular customers.

\section{Severe restrictions on investment cost, talents and technology}

Capital

For small and medium enterprises, it is relatively difficult to establish or purchase CRM by themselves, because their capital is limited. Actual investment cost cannot meet their actual demand, and they may undertake certain risks. In addition, the financing of small and medium enterprises in China are influenced by numerous factors in present stage, so their financing channel is too narrow. 
They have to operate through enterprise capital accumulation, and cannot gain good external capital support.

\section{Talents}

Talent shortage and deficiency of small land medium enterprises will affect effective implementation of CRM. Firstly, in small land medium enterprises, administrative staffs and leaders fail to effectively cognize and support CRM, so there is short of project execution and leadership. Secondly, CRM team does not own good experience and implementation skills. The primary cause is that the organization is not complete and the number of functional personnel is sufficient in CRM team building process ${ }^{[6]}$.

\section{Technology}

Technical level of small and medium enterprises in China is relatively low. They generally depend on manual work or semi-automation. Few enterprises can completely achieve mechanized production. Thus, automated production is very rare in the enterprises. The application of such laggard production mode and production technology and hysteretic management level will result in serious effects on CRM. Secondly, CRM has variability and expansibility to some extent, so the discrepancy with small and medium enterprises may exist. This also indicates CRM implementation has certain risks. Thus, it is required to choose CRM according to customers' real conditions.

\section{Influence of external environment factor}

Firstly, the implementation foundation of small and medium enterprises is relatively weak. Very few enterprises can completely achieve office automation in enterprise information system construction and application process. This greatly results in serious shortage of information data acquisition, quantity and quality in CRM. Secondly, the general environment of domestic market competitions is not very normative, so many enterprise leaders depend on and apply previous successful experience. Besides, they lack necessary trust in the idea of CRM, which results in the difficulty in implementing CRM.

\section{Countermeasures to implement CRM in small and medium enterprises}

During implementation of CRM, small and medium enterprises has a great gap with some large enterprises, because business division, organizational structure, working process and information quantity of large enterprises are complex and standard. Thus, their CRM has certain complexity ${ }^{[7]}$. CRM applied in small and medium enterprises is much simpler, but business division is not clear. Thus, enterprises have certain flexibility in actual operation process. The application of CRM by small and medium enterprises has the following features. The following should be done well to apply CRM in small and medium enterprises.

\section{Implement cost control for CRM application}

CRM application process not just includes preparation, development cost, operation cost and maintenance cost, but also involves staff cost. For small and medium enterprises which are short of capital level and strength, it is very necessary to control implementation cost. Both self-supervision and purchase need the support of development cost in the implementation period. Besides, the maintenance cost is also large. Therefore, very effective outsourcing service can be chosen.

\section{Implement and control potential risks in the implementation process}

CRM will have certain risks in the implementation period, such as cost risk, information disclosure risk and uncertain risk. Once any risk happens, the operation and development of small and medium enterprises will be seriously affected so that their reform ability, comprehensive level and competition ability stand still. Even, they will retrogress. Thus, small and medium enterprises must prevent these risks. Only in this way, they can promote enterprise development and growth by making the best of CRM advantages. Firstly, small and medium enterprises must improve employees' specialty accomplishment and technical level and make them well apply CRM so as to better serve customers $^{[8]}$. Secondly, small and medium enterprises should confirm products and services according to customer demand and production level, seriously check and evaluate products and services as well as construct good responsibility mechanism so as to make CRM really implemented. 
Finally, it is required to maintain the contracts signed by enterprises and customers and maintain enterprise reputation, specify responsibilities and rights of both parties, solve data problems in the contracts and reduce hidden dangers of data security as far as possible.

\section{Control CRM implementation process}

Progressive mode must be followed during implementation of CRM. CRM shall not be applied without any preparation. This will give play to its functions, and affect enterprise development and improvement ${ }^{[9]}$. Therefore, the control should be done from the following aspects. Firstly, it is required to publicize and promote CRM idea in enterprises and improve corresponding technology. Meanwhile, enterprises should improve employees' participation with pertinence, make them cognize CRM and let CRM effectively fuse with enterprises. Secondly, CRM hardware design should be improved with pertinence, and modularized mode is applied for implementation. In the application period, enterprises may let one or more departments implement CRM on the basis of original hardware facilities. After certain achievements' are gained, CRM may be popularized and implemented in the whole enterprises. Finally, CRM should be well maintained and valued. CRM is a dynamic and long-term process. Only when the above work is done well, good effects can be gained, and small and medium enterprises can develop better.

\section{Conclusion}

In one word, implementation and application of CRM in small and medium enterprises is not just the actual demand of enterprise development, but also an inexorable trend of era progress. Thus, it is required to pay attention to CRM. However, since small and medium enterprises in China lack CRM application experience and level, some problems will exist in actual implementation of it. It is necessary to fully cognize and know CRM, use corresponding measures to solve problems and effectively drive development of small and medium enterprises.

\section{References}

[1] Deng Xiaoyong, CRM problems, causes and countermeasures of real estate enterprises, Industrial \& Science Tribune, 2015(3):195-196.

[2] Fang Hongxing, Zhang Yong, Trade of supplier/customer relation type, earnings management and auditor's decision, Accounting Research, 2016(1):79-86.

[3] Yu Xiuwei, Tian Li, CRM strategy, Market Modernization, 2015(7):114-114.

[4] Pang Fei, Exploration of CRM in network environment, Journal of Huanghe S\&T University, 2015,17(1):40-42.

[5] Wang Huimin, Study on operation capital management mode based on customer relation - case study of JY Company, Ocean University of China, 2015.

[6] Sun Qingzhao, Exploration of CRM strategy about enterprise marketing management, Operator, 2015(1):48-48.

[7] Ding Yan, Study on CRM of monopoly enterprises in China, China Business \& Trade, 2015(2):8-9.

[8] Zhu Yifan, Application of CRM in enterprise marketing management, Market Modernization, 2015(23):110-111.

[9] Jiang Mengyang, Function of CRM in enterprise marketing management, Business Storyies, 2015(9):112-113. 